\title{
Design Blocks in Simulink to Detection Singularity in the Workspace of Gough-Stewart Robot Manipulator
}

\author{
Hassan Mohammed Alwan Riyadh Ahmed Sarhan \\ Mechanical Engineering Department, University of Technology, Baghdad-Iraq \\ 20071@uotechenology.edu.iq me.21328@uotechnology.edu.iq
}

\begin{tabular}{|l|l|l|}
\hline Submission date:- 11/10/2018 & Acceptance date:- 22/10/2018 & Publication date:- 9/1/2019 \\
\hline
\end{tabular}

\begin{abstract}
:
This work deals with Gough-Stewart robot manipulator, which has six degrees of freedom, six actuators, fixed base, and moving platforms. Here, the Jacobian matrix derived to detect the singular point in the workspace for manipulator at determinant of Jacobian matrix equal to zero, then derived the equation of motion from the dynamic analysis by Lagrange method to verify the singular points with Jacobian where the forces increase rapidly at this point. Finally, design blocks in Simulink include the Jacobian matrix and the equations of motion to detection the singularities at any time for current input parameters (X, Y, Z, $\alpha, \beta, \gamma)$, where the determinant of the Jacobian equal to zero at maximum forces.
\end{abstract}

Key words: Robot, Gough-Stewart, Simulink, Jacobian, Dynamic analysis, Singularities.

\section{Introduction:}

Parallel manipulators Fig (1.A) are more important than serial manipulators Fig (2.B) in dynamic performance, load capacity, rigidity, and stability[1]. Where the workspace of parallel smaller compare with serial manipulators and the control system is very difficult due to the complexity in the calculation of forward kinematics and dynamic analysis [2]. In the last time, the subject of the parallel robot widely studied in the field of the robotic research because the parallel manipulator can be done some works, which cannot be done in serial manipulators [3]. First the parallel robot used as flight simulator by in 1965 [4]. The best type of the parallel manipulator is Gough-Stewart manipulator proposed by Stewart [5], it is also called closed loop mechanism consist of fixed base, six actuators, moving platform, and joints, where the number of actuators determine the degree of freedom for the moving platform [6]. Due to the nature of the manipulator the singular points may be appear in the workspace during the forward kinematics problems [7]. The workspace of the Gough-Stewart manipulator has different type of singularities such as configuration and actuation singularities [8], This workspace depends on the range motion of joints and moving platform [9]. The singularities may exist in one or more location in this workspace, at this point the moving platform loss or gain one degree of freedom [10], and the platform becomes uncontrolled [11]. The mechanism of manipulator may be breakdown at singular points because the actuators forces become very large at this points [12].

In this search, the singular points in the workspace of Gough-Stewart manipulator detected by using the kinematics and dynamic analysis in Simulink package.

Journal of University of Babylon for Engineering Sciences by University of Babylon is licensed under a Creative Commons Attribution 4.0 International License. 

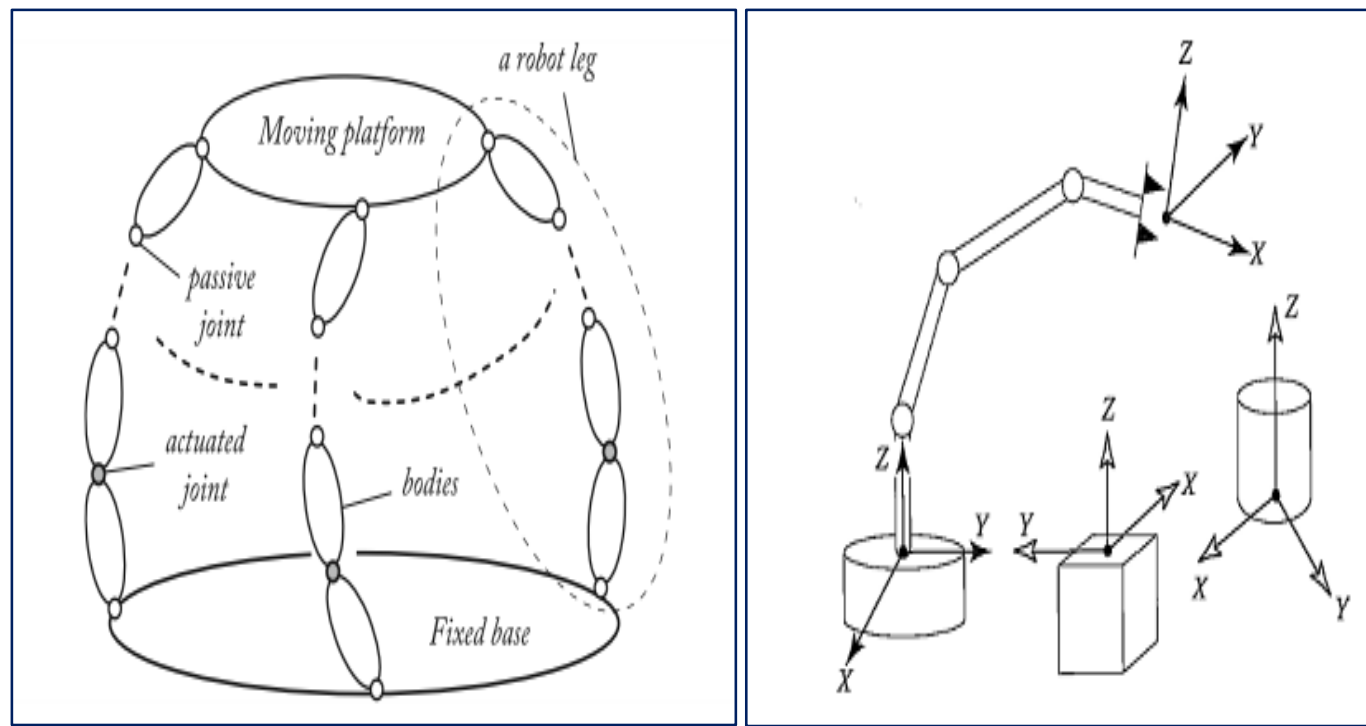

Fig (1): A. Parallel Robot Manipulator, B. Serial Robot Manipulator.

\section{1- Theoretical work:}

The model of the manipulator consists of the fixed base and moving platform, six linear actuators which are connected to the base by universal joints (have two degrees of freedom) and connected with the moving platform by a ball joint (have three degrees of freedom) as shown in Fig (2) [13].
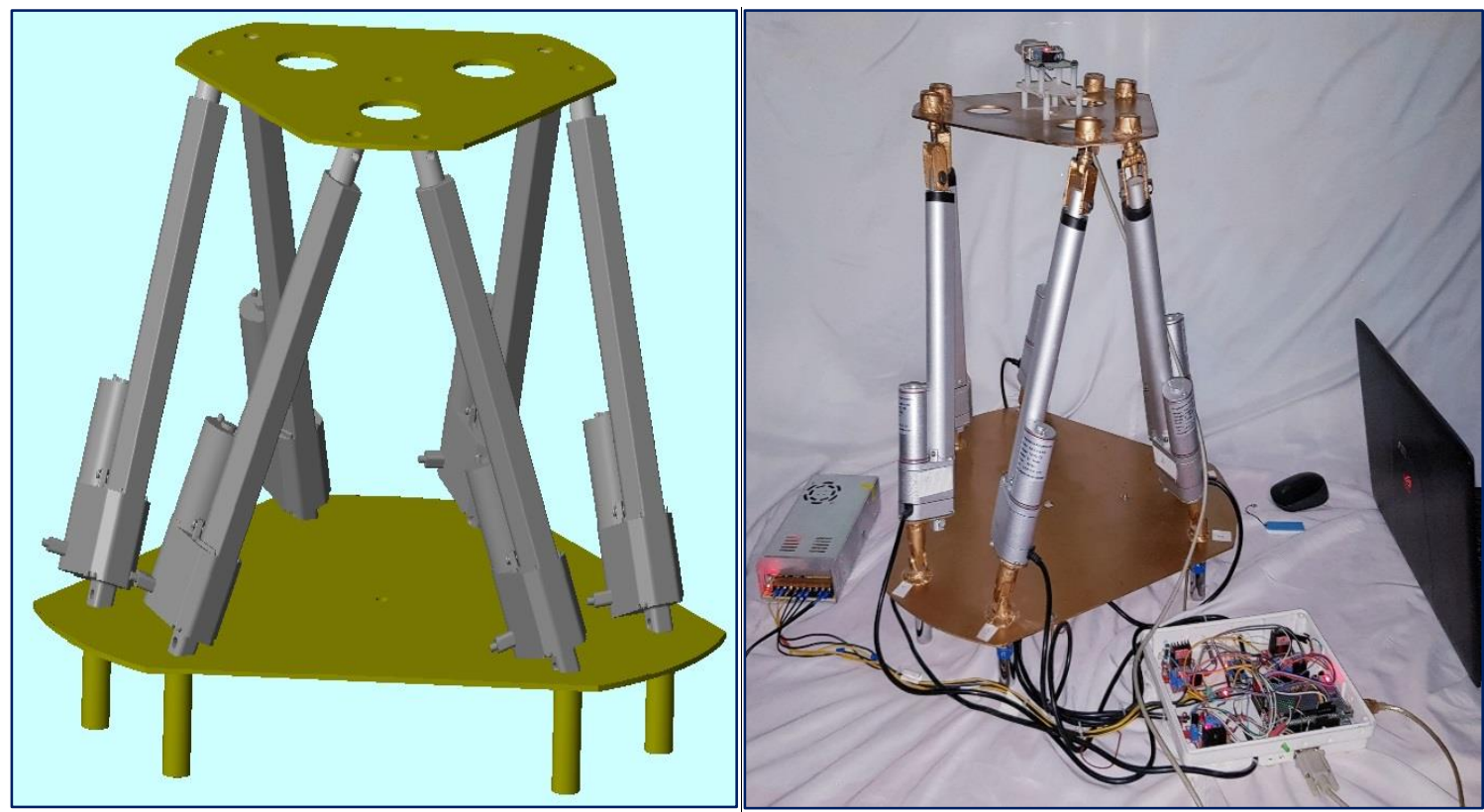

Fig (2): The model of Gough-Stewart manipulator.

\section{2- Jacobian Matrix of Gough-Stewart Manipulator Robot:}

The Jacobian matrix obtained from the relationship between the velocities of the moving platform and the velocities of the actuators [14].

As shown in the geometry of the manipulator in the Fig (3), the link input denoted by $\dot{L}=$ $\left[\begin{array}{llllll}\dot{L}_{1} & \dot{L}_{2} & \dot{L}_{3} & \dot{L}_{4} & \dot{L}_{5} & \dot{L}_{6}\end{array}\right]^{T}$, and the output of the platform denoted by $\dot{x}=\left[\begin{array}{cccccc}\dot{X} & \dot{Y} & \dot{Z} & \dot{\alpha} & \dot{\beta} & \dot{\gamma}\end{array}\right]^{T}$, 
where the linear velocity of the platform $\dot{v}_{p}=\left[\begin{array}{lll}\dot{X} & \dot{Y} & \dot{Z}\end{array}\right]^{T}$ and the angular velocity of the platform $\dot{w}_{p}=$ $\left[\begin{array}{ccc}\dot{\alpha} & \dot{\beta} & \dot{\gamma}\end{array}\right]^{T}$. The jacobian matrix can be obtained by derived the velocity of each link as shown:

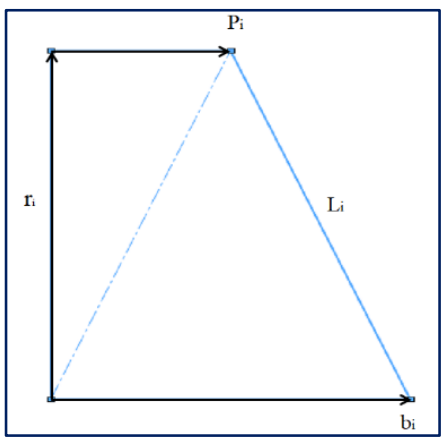

Fig (3): Scheme of the i leg.

$$
\begin{aligned}
& { }^{G} P_{i}=r_{0}+{ }^{G} R_{L} *{ }^{L} P_{i}[15] \\
& { }^{G} P_{i}=\left[\begin{array}{lll}
X & Y & Z
\end{array}\right]+\left[\begin{array}{lll}
r_{11} & r_{12} & r_{13} \\
r_{21} & r_{22} & r_{23} \\
r_{31} & r_{32} & r_{33}
\end{array}\right] *\left[\begin{array}{l}
P_{X i} \\
P_{Y i} \\
P_{Z i}
\end{array}\right]
\end{aligned}
$$

\section{Where:}

$$
\begin{aligned}
& r_{11}=\cos (\gamma) \cos (\beta) \\
& r_{12}=\cos (\gamma) \sin (\beta) \sin (\alpha)-\sin (\gamma) \cos (\alpha) \\
& r_{13}=\cos (\gamma) \sin (\beta) \cos (\alpha)+\sin (\gamma) \sin (\alpha) \\
& r_{21}=\sin (\gamma) \cos (\beta) \\
& r_{22}=\sin (\gamma) \sin (\beta) \sin (\alpha)+\cos (\gamma) \cos (\alpha) \\
& r_{23}=\sin (\gamma) \sin (\beta) \cos (\alpha)-\cos (\gamma) \sin (\alpha) \\
& r_{31}=-\sin (\beta) \\
& r_{32}=\cos (\beta) \sin (\alpha) \\
& r_{33}=\cos (\beta) \cos (\alpha)
\end{aligned}
$$
such as:

By derivative equation (1) with respect to time to get the velocity of the attached points at platform

$$
{ }^{G} \dot{P}_{L}=\dot{v}_{p}+\dot{w}_{p} \times R_{L}^{G} *{ }^{G} R_{L}
$$

Where the length rate of $i$ leg can be obtain from the equation:

$$
\begin{aligned}
\dot{L}_{i} & ={ }^{G} P * \vec{U}_{i} \\
\vec{U}_{i} & =\frac{\overrightarrow{b_{l} P_{l}^{G}}}{\left|b_{i} P_{i}^{G}\right|} \\
\vec{U}_{i} & =U_{x i} \vec{\imath}+U_{y i} \vec{\jmath}+U_{z i} \vec{k}
\end{aligned}
$$




$$
\dot{L}_{i}=\dot{r}_{0} * \vec{U}_{i}+w \times\left({ }^{G} R_{L} *{ }^{L} P_{i}\right) \cdot \vec{U}_{i}
$$

The final equation may be written as:

$$
\begin{aligned}
& \dot{L}_{i}=J^{-1} *\left[\begin{array}{llllll}
\dot{X} & \dot{Y} & \dot{Z} & \dot{\alpha} & \dot{\beta} & \dot{\gamma}
\end{array}\right]^{T} \\
& J^{-1}=\left[\begin{array}{llll}
U_{x 1} & U_{y 1} & U_{z 1} & \left(\left({ }^{G} R_{L} *{ }^{L} P_{1}\right) \times \vec{U}_{1}\right)^{T} \\
U_{x 2} & U_{y 2} & U_{z 2} & \left(\left({ }^{G} R_{L} *{ }^{L} P_{2}\right) \times \vec{U}_{2}\right)^{T} \\
& & & \left(\left({ }^{G} R_{L} *{ }^{L} P_{3}\right) \times \vec{U}_{3}\right)^{T} \\
U_{x 3} & U_{y 3} & U_{z 3} & \left(\left({ }^{G} R_{L} *{ }^{L} P_{4}\right) \times \vec{U}_{4}\right)^{T} \\
U_{x 4} & U_{y 4} & U_{z 4} & \left(\left({ }^{G} R_{L} *{ }^{L} P_{5}\right) \times \vec{U}_{5}\right)^{T} \\
U_{x 5} & U_{y 5} & U_{z 5} & \left(\left({ }^{G} R_{L} *{ }^{L} P_{6}\right) \times \vec{U}_{6}\right)^{T}
\end{array}\right]
\end{aligned}
$$

\section{3- Dynamic Equations of Gough Stewart:}

The difference between the kinetic and potential energy referred to the Lagragian function [16]:

$\mathcal{L}=K . E-P . E$

The final Lagrange equation as presented by eq.10 includes the mass matrix $M(X)$, Coriolis matrix $C(X, \dot{X})$, and gravity matrix $G(X)$

$$
M(X) \ddot{X}+C(X, \dot{X}) \dot{X}+G(X)=\tau
$$

Gough-Stewart manipulator divided into two subsystems the upper moving platform and the six legs. The kinetic and potential energy of these subsystems should be computed to derive the dynamic equations for the Gough-Stewart manipulator.

\section{1- Dynamic analysis of the upper moving platform:}

Here the Lagrange formulation for the dynamic analysis (equation 10) applied on the moving platform for the Gough-Stewart manipulator to obtain its mass matrix $(\mathrm{M})$, Coriolis matrix $(V)$ and gravitational matrix $(G)$, which obtained after calculate the kinetic and potential energy for the moving platform as shown in the equations below:

$$
\begin{aligned}
& M_{p l}=\left[\begin{array}{cc}
m_{p l}[\mathrm{I}]_{3 X 3} & 0_{3 X 3} \\
0_{3 X 3} & I_{p l}
\end{array}\right] \\
& C(x)_{p l} \dot{x}=\frac{1}{2}\left[\begin{array}{cc}
0_{3 X 3} & 0_{3 X 3} \\
0_{3 X 3} & w_{p l} x I_{p l}
\end{array}\right] \dot{x} \\
& G_{p l}=\left[\begin{array}{llllll}
0 & 0 & m_{p l} g & 0 & 0 & 0
\end{array}\right]^{T}
\end{aligned}
$$




\section{2- Dynamic analysis of the linkages:}

The dynamic analysis of the linkages of the Gough-Stewart manipulator robot done by decomposing each linkages into two parts (only rotate motion), the lower part and the upper part (rotate and linear motion) as shown in Fig (4). Assuming the center of the masses of each part are considered to be located at $S_{1}$ and $S_{2}$ from its ends and their masses denoted by $m_{1}$ and $m_{2}$.

This analysis done by calculating the kinetic energy and potential energy for the linkages to obtain the mass, Coriolis, and gravity matrices as below:

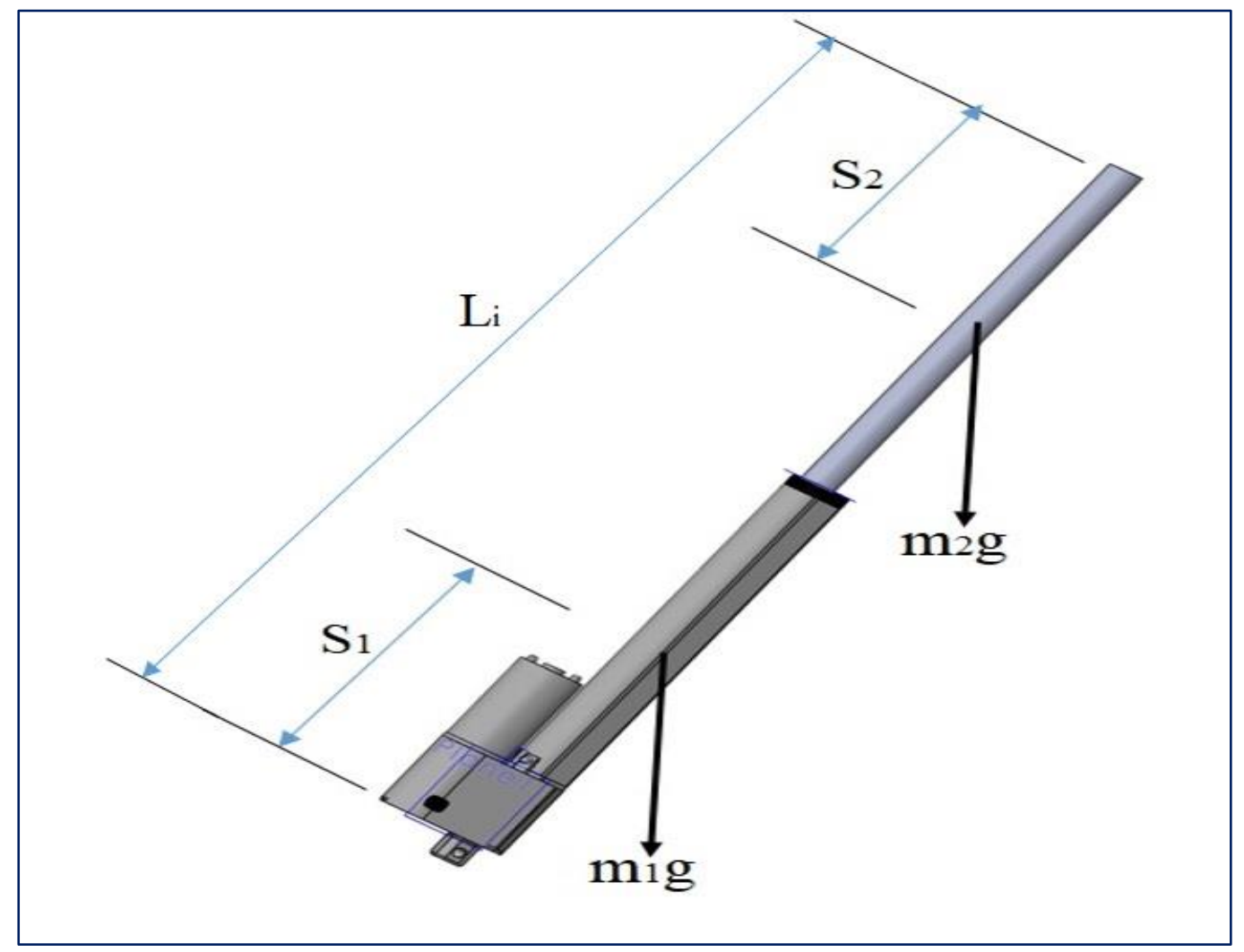

Fig (4): Two parts of i linkages.

\section{Where:}

$S_{1}$ : the distance from the lower joint to the center of the lower part of i leg.

$S_{2}$ : the distance from the upper joint to the center of the upper part of $i$ leg.

$m_{1}$ : the mass of the lower part of $i$ leg.

$m_{2}$ : the mass of the upper part of $i$ leg.

$$
M_{L i}=m_{2} \vec{U}_{i} \vec{U}_{i}^{T}-m_{e q} \vec{U}_{i}^{2} \times-\frac{1}{\left|L_{i}\right|^{2}} I_{e q} \vec{U}_{i}^{2} \times
$$

$C_{L i}\left(x_{L i}, \dot{x}_{L i}\right) \dot{x}_{L i}=\left(-\frac{1}{\left|L_{i}\right|^{2}} m_{2} S_{2} \vec{U}_{i} \dot{x}_{L i}{ }^{T} \vec{U}_{i}{ }^{2} \times-\frac{2}{\left|L_{i}\right|}\left(\frac{1}{\left|L_{i}\right|} m_{2} S_{2}-\frac{1}{\left|L_{i}\right|^{2}}\left(I_{e q}+\right.\right.\right.$

$\left.\left.\left.\left|L_{i}\right|^{2} m_{e q}\right)\right)\left|\dot{L}_{i}\right| \vec{U}_{i}^{2} \times\right) \dot{x}_{L i}$ 


$$
G_{L i}=\frac{\partial P_{L i}}{\partial x_{L i}}=g\left(\left(m_{1} S_{1}+m_{2}\left(\left|L_{i}\right|-S_{2}\right)\right) \vec{U}_{i}^{2} \times-m_{2} \vec{U}_{i} \vec{U}_{i}^{T}\right)
$$

\section{Dynamic analysis of the whole Gough-Stewart manipulator robot:}

To evaluate the final dynamic equations of the manipulator, the coordinates of the linkages $x_{L i}$ in terms of the general coordinates of the moving platform $x_{p l}$ to obtain the general mass, Coriolis, and gravity matrices, which used in Lagrange formulation to find the forces on the linkages.

$$
\begin{aligned}
& \dot{x}_{L i}=J_{i} \dot{x}_{p l} \\
& J_{i}=\left[\begin{array}{ll}
\mathrm{I}_{3 \times 3} & -{ }^{L} P_{i} \times
\end{array}\right] \\
& \ddot{x}_{L i}=J \ddot{x}_{p l}+\dot{J} \dot{x}_{p l} \\
& \dot{J}_{i}=\left[\begin{array}{ll}
0_{3 \times 3} & -\left(w_{p l} \times{ }^{L} P_{i}\right) \times
\end{array}\right]=\left[\begin{array}{ll}
0_{3 \times 3} & -w_{p l} \times{ }^{L} P_{i} \times+{ }^{L} P_{i} \times w_{p l} \times
\end{array}\right]
\end{aligned}
$$

The Lagrange formulation for the linkages can be written as:

$$
\begin{aligned}
& M_{L i} \ddot{x}_{L i}+C_{L i} \dot{x}_{L i}+G_{L i}=\left(J^{-1}\right)^{T} F_{L i} \\
& M_{L i}\left(J_{i} \ddot{x}_{p l}+\dot{J}_{i} \dot{x}_{p l}\right)+C_{L i}\left(J_{i} \dot{x}_{p l}\right)+G_{L i}=\left(J^{-1}\right)^{T} F_{L i}
\end{aligned}
$$

Hence the mass, Coriolis, and gravity matrices for whole manipulator can be written as:

$$
\begin{aligned}
& M=M_{p l}+\sum_{i=1}^{i=6} M_{L i n i} \\
& C=C_{p l}+\sum_{i=1}^{i=6} C_{L i n i} \\
& G=G_{p l}+\sum_{i=1}^{i=6} G_{L i n i}
\end{aligned}
$$

$$
\left(J^{T}\right)^{-1}\left(M \ddot{x}_{p l}+C \dot{x}_{p l}+G=F\right.
$$

Where:

$$
\begin{aligned}
M_{\text {Lini }} & =J_{i}^{T} M_{L i} J_{i} \\
C_{\text {Lini }} & =J_{i}{ }^{T} M_{L i} \dot{J}_{i}+J_{i}{ }^{T} C_{L i} J_{i} \\
G_{\text {Lini }} & =J_{i}{ }^{T} G_{L i} J_{i}
\end{aligned}
$$

\section{6- Modeling Blocks in Simulink:}

In this paper the inverse dynamic model in the last equation employed to calculate the forces of the linkages, which need to compute the mass, Coriolis, gravity, and jacobian matrices based on the input parameters, the overall modeling of the dynamic analysis have been done in the Matlab software (Simulink blocks), which represented in the Fig (5). 
Journal of University of Babylon for Engineering Sciences, Vol. (27), No. (1): 2019.

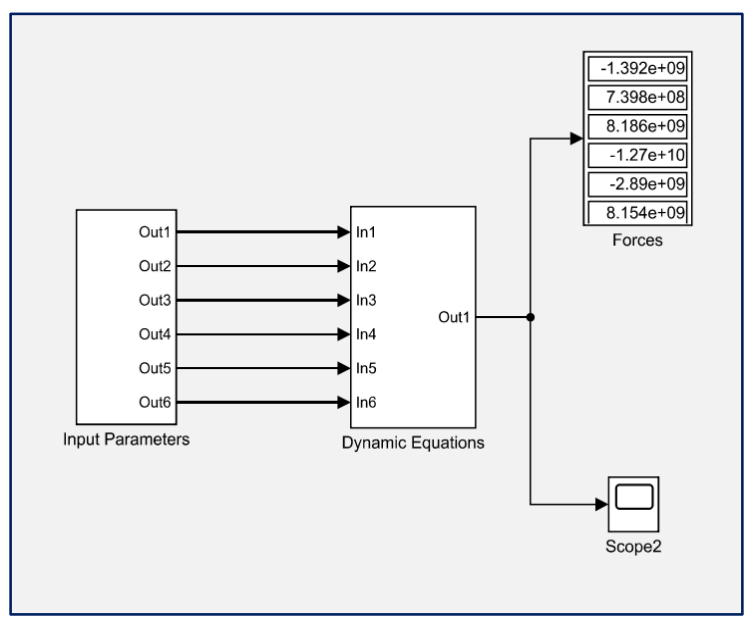

Fig (5): Dynamic model in Simulink.

The subsystems of the inputs parameters include position, orientation, translation and angular velocities, and translation and angular acceleration for the center of the moving platform, as shown in the Fig (6) and Fig (7), lead to commute the forces in the last block Fig (5).

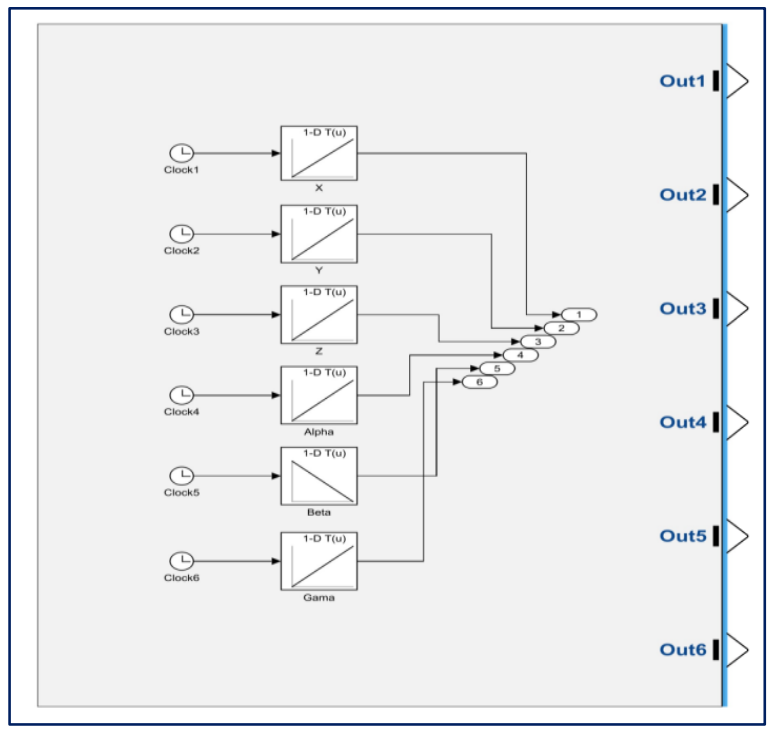

Fig (6): Position and orientation coordinates. 
Journal of University of Babylon for Engineering Sciences, Vol. (27), No. (1): 2019.

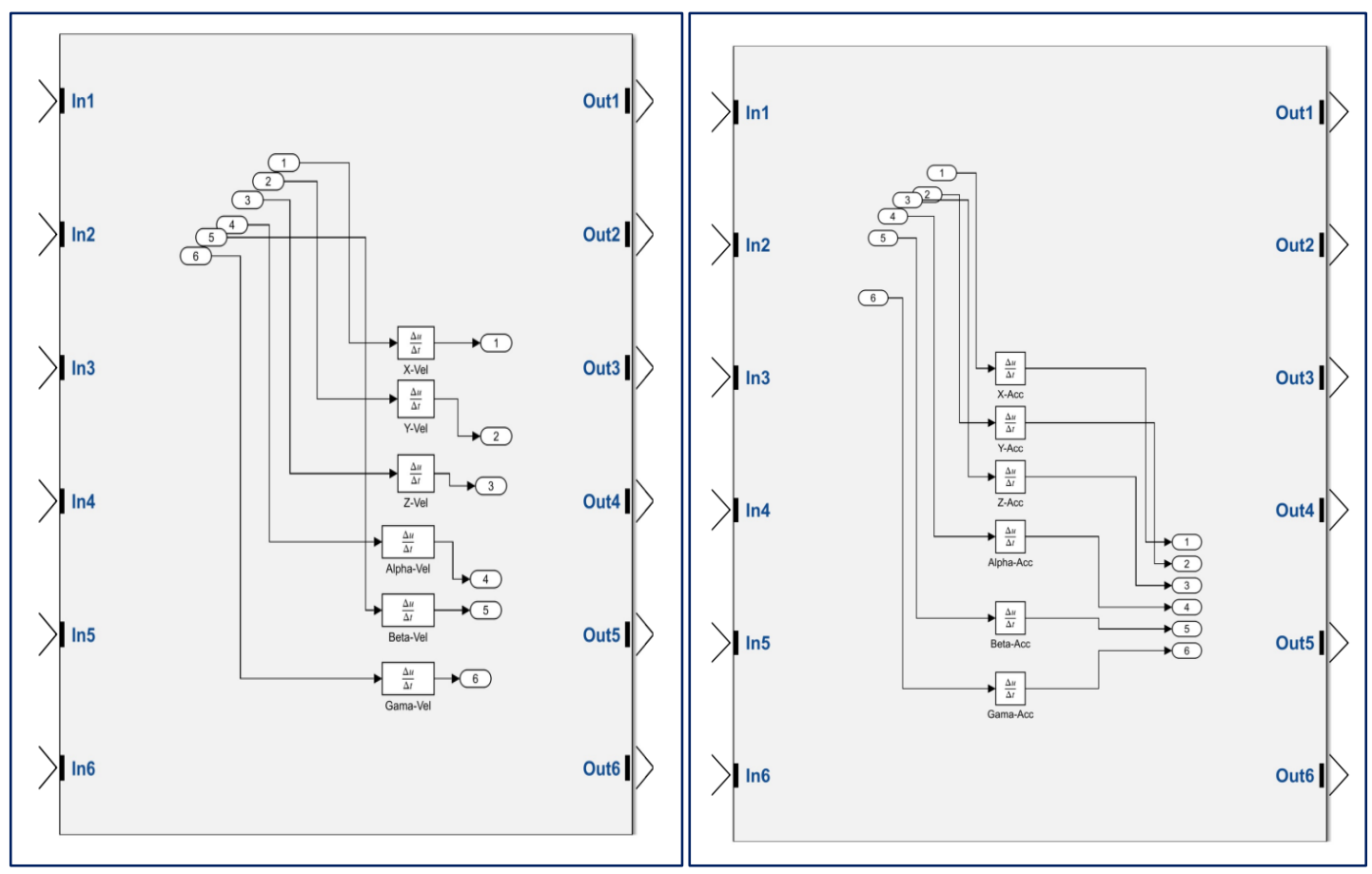

Fig (7): Velocity and acceleration (Translation and angular).

And the subsystems of the dynamic equations consist of invers kinematics blocks to compute the lengths, Jacobian block, mass matrix, Coriolis matrix, and gravity matrix, Fig (8) and Fig (9). Finally, the overall blocks shown in Fig (10).

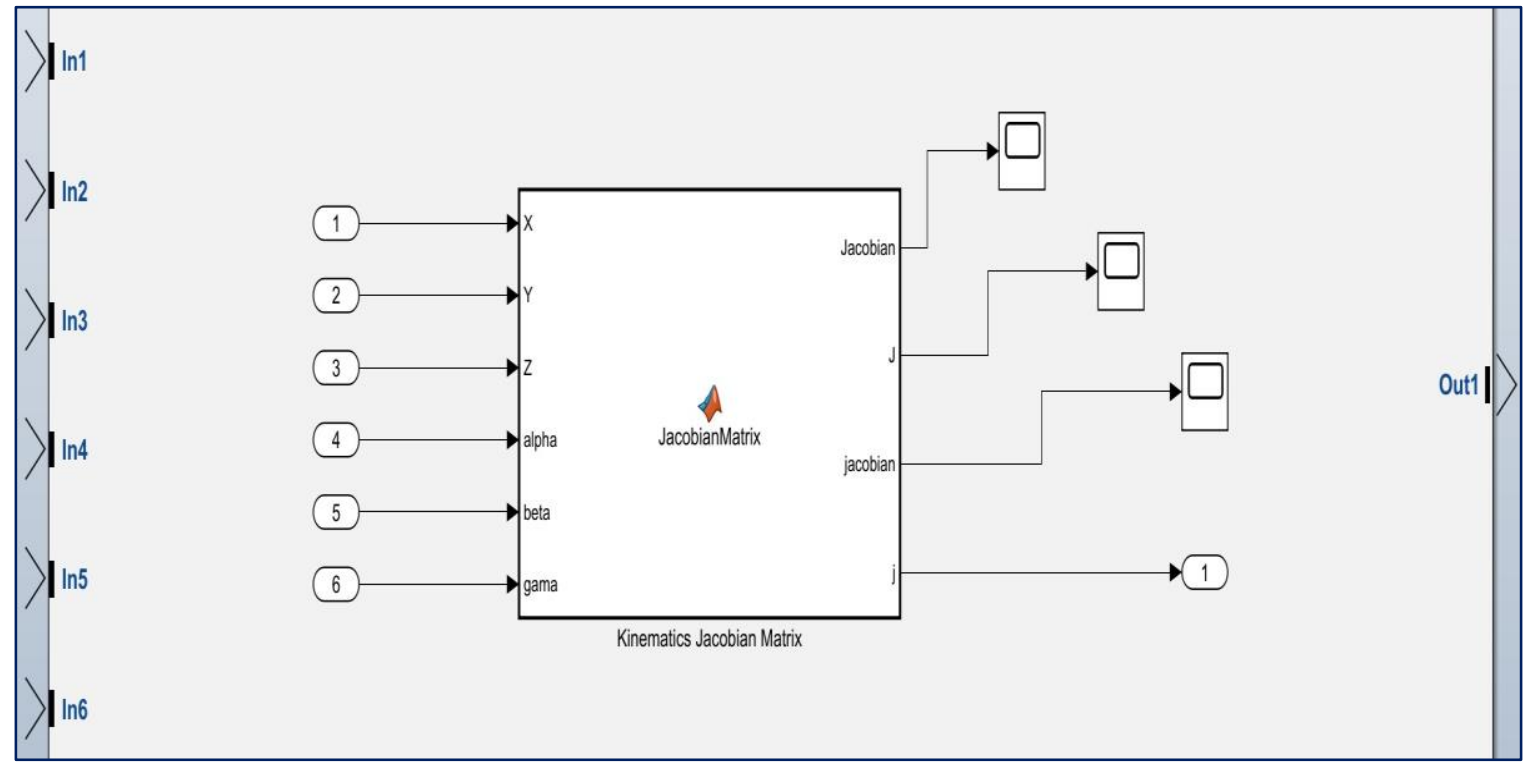

Fig (8): Inverse kinematics and jacobian blocks. 
Journal of University of Babylon for Engineering Sciences, Vol. (27), No. (1): 2019.

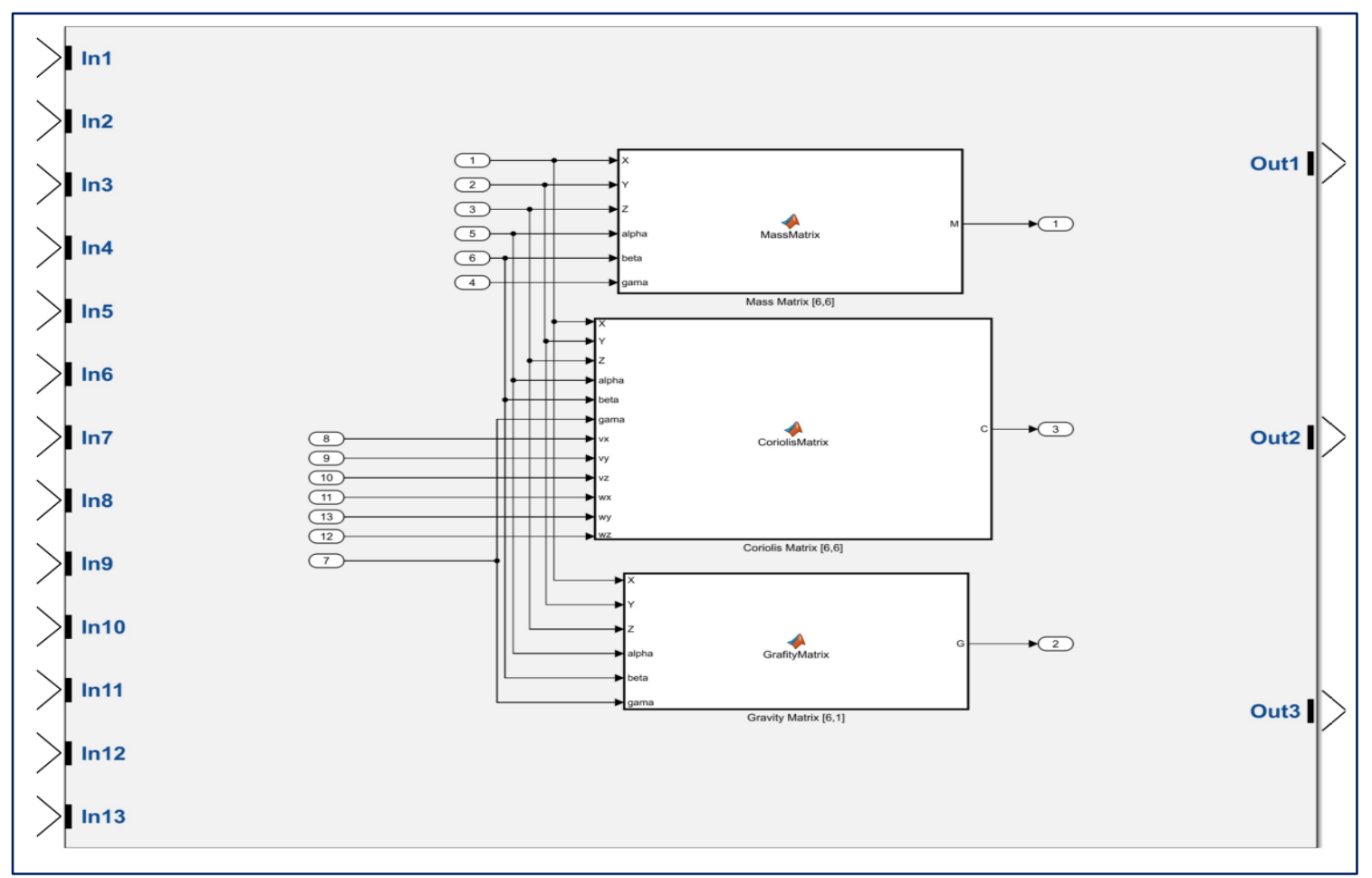

Fig (9): Mass, Coriolis, and Gravity matrices in Simulink.

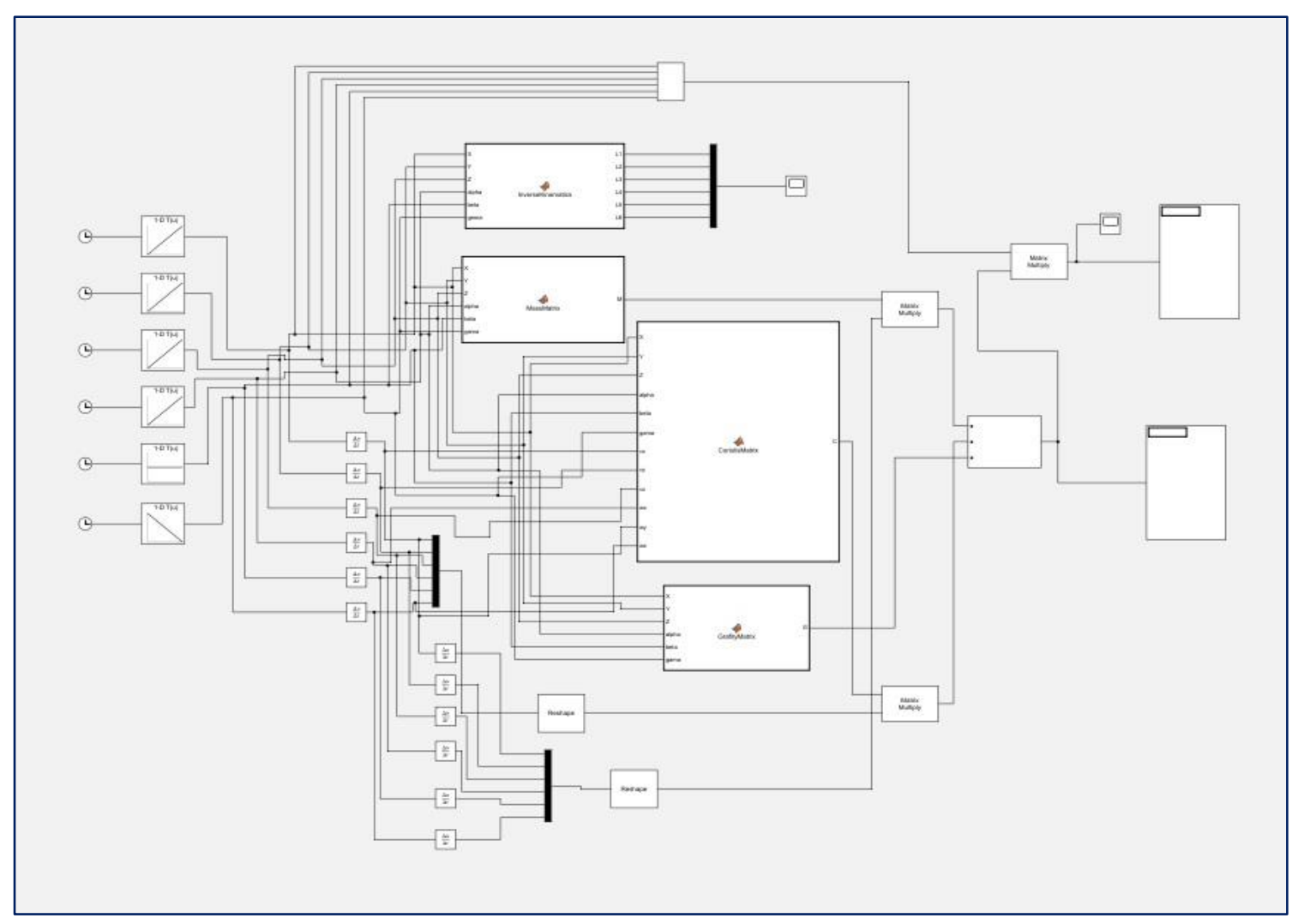

Fig (10): All blocks in Simulink. 


\section{7- Results and Discussion:}

The model of Gough-Stewart robot manipulator which used in this paper has several singular points in its workspace lead to loss or gain one or more degree of freedom, these points detection here by building blocks diagram in Matlab (Simulink) which contain the equations of the Jacobian matrix and dynamic analysis. When the singular point locates on the configuration of the trajectory, the determinant of Jacobian matrix equal to zero and the forces reached to maximum value.

The input parameters include the position and orientation (X, Y, Z, $\alpha, \beta, \gamma)$ of the moving platform in global coordinates used in the these blocks represented in Fig (11), and the linear and angular velocities, the linear and angular acceleration obtained by the first derivative of the position and orientation Fig (12) from the first and second derivative for these parameters Fig (13).

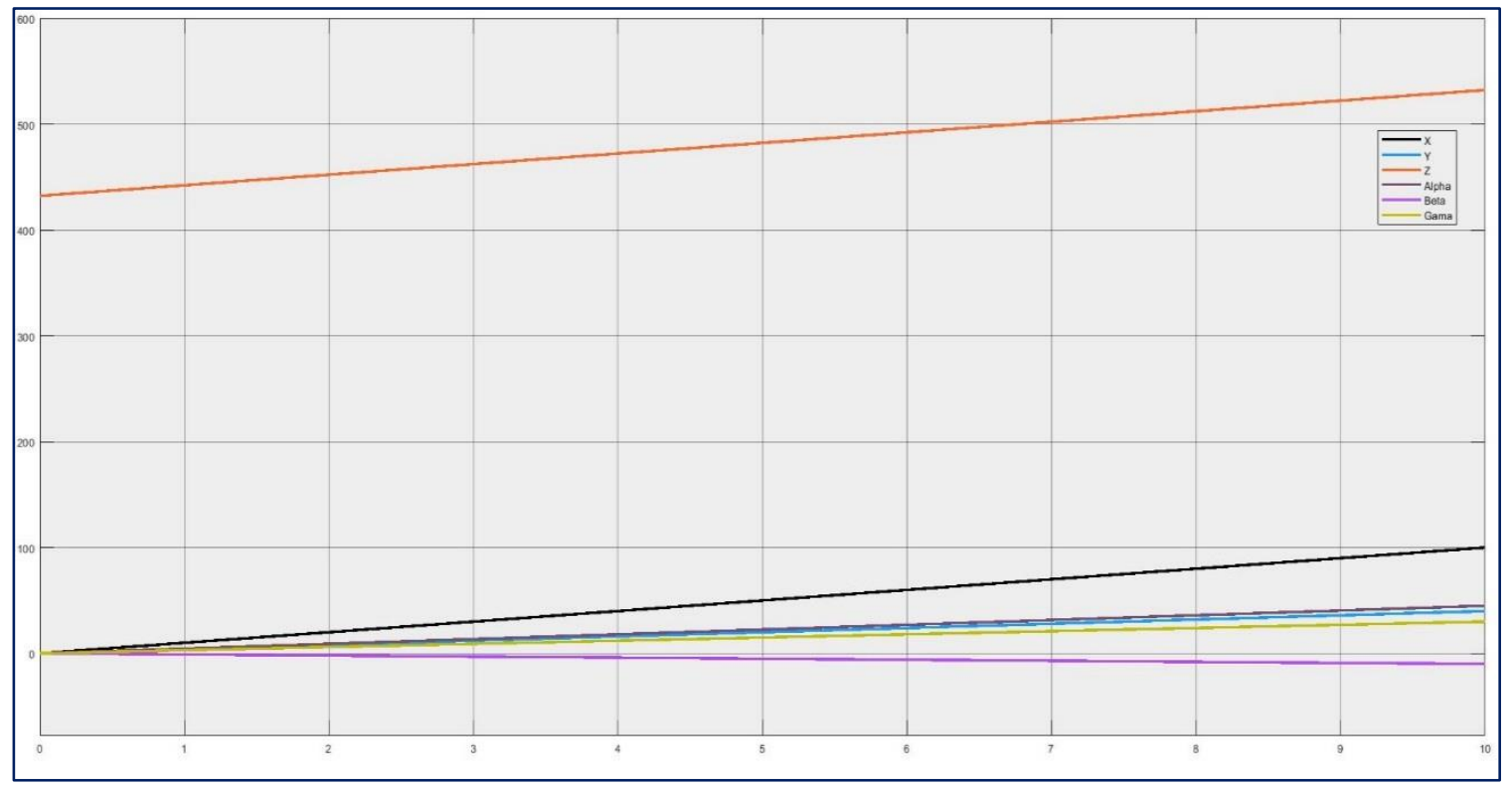

Fig (11): Inputs parameters (Position and orientation of moving platform).

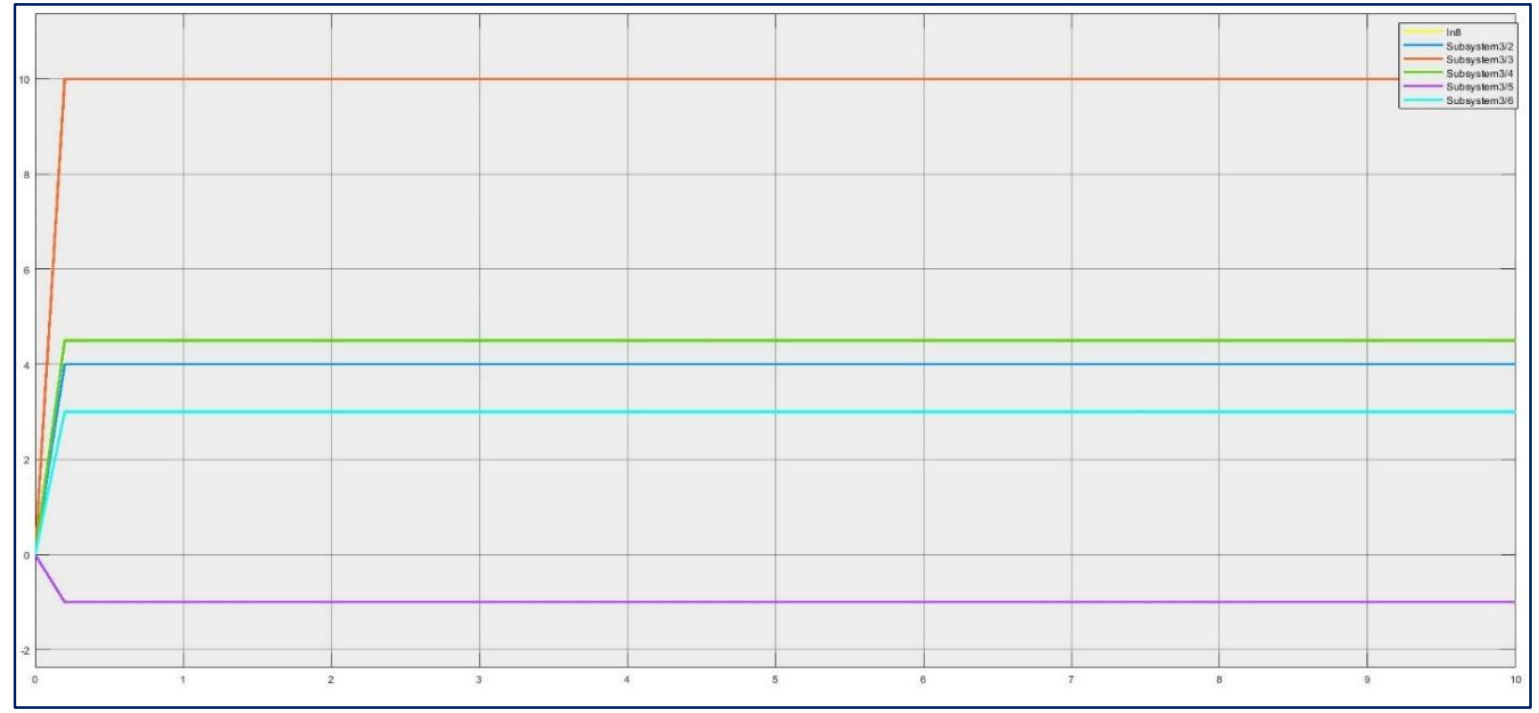

Fig (12): Results of velocities. 
Journal of University of Babylon for Engineering Sciences, Vol. (27), No. (1): 2019.

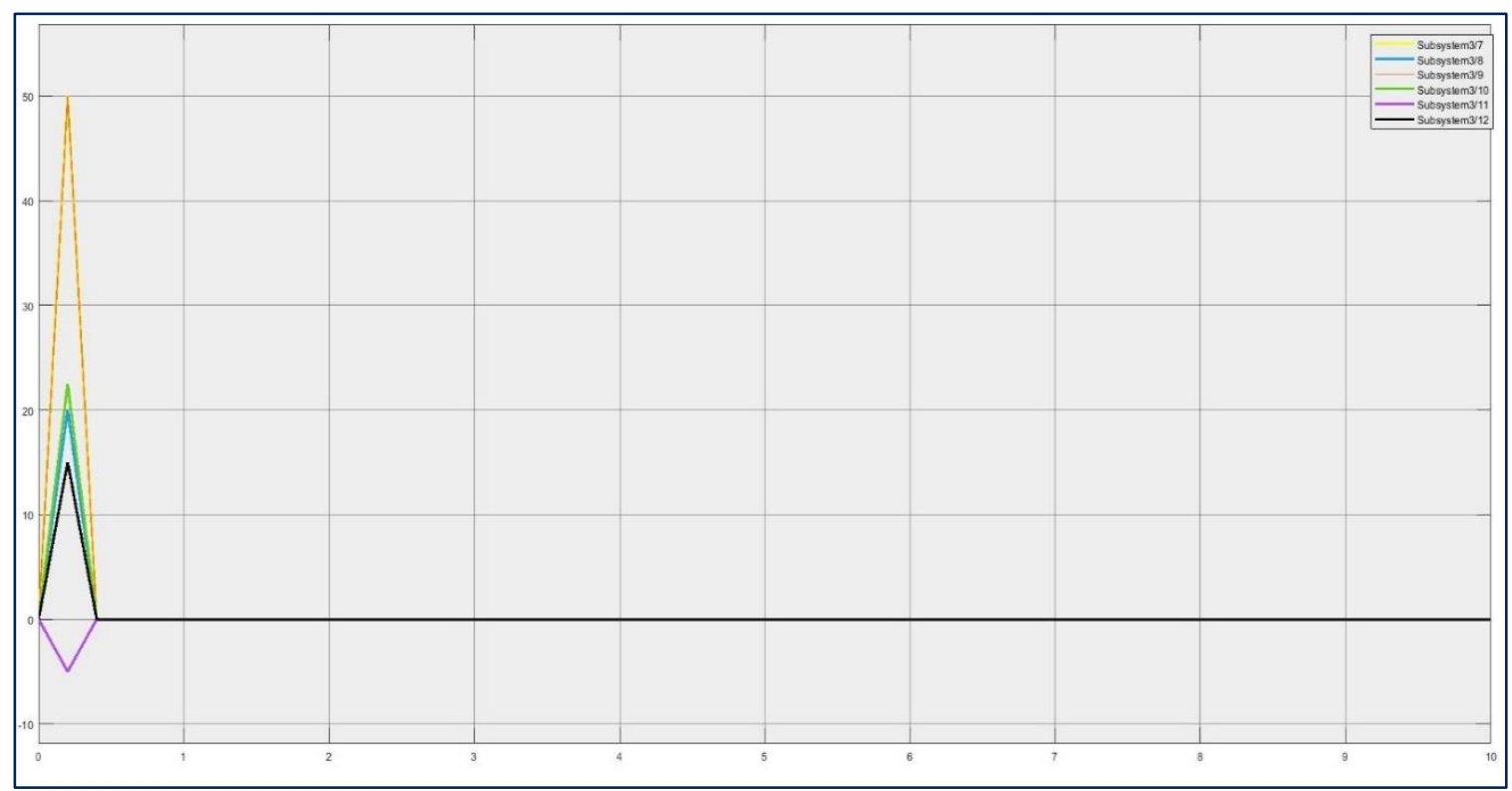

Fig (13): Results of acceleration.

From the inverse kinematics problems the lengths of the each linkages from start to end point Fig(14), which used to explain how the moving platform become at start and end point as shown in Fig(15).

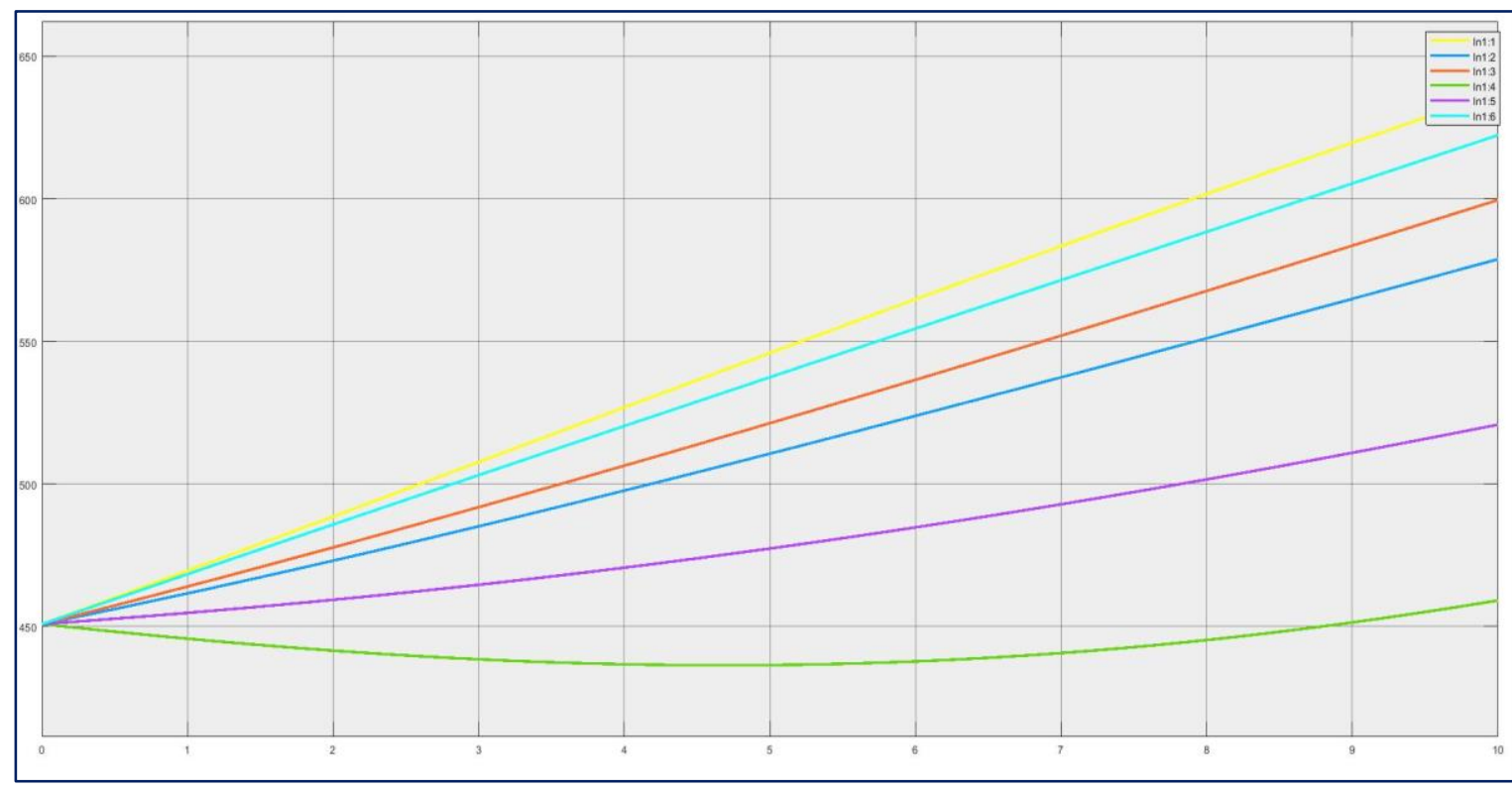

Fig (14): Results of lengths of the linkages. 

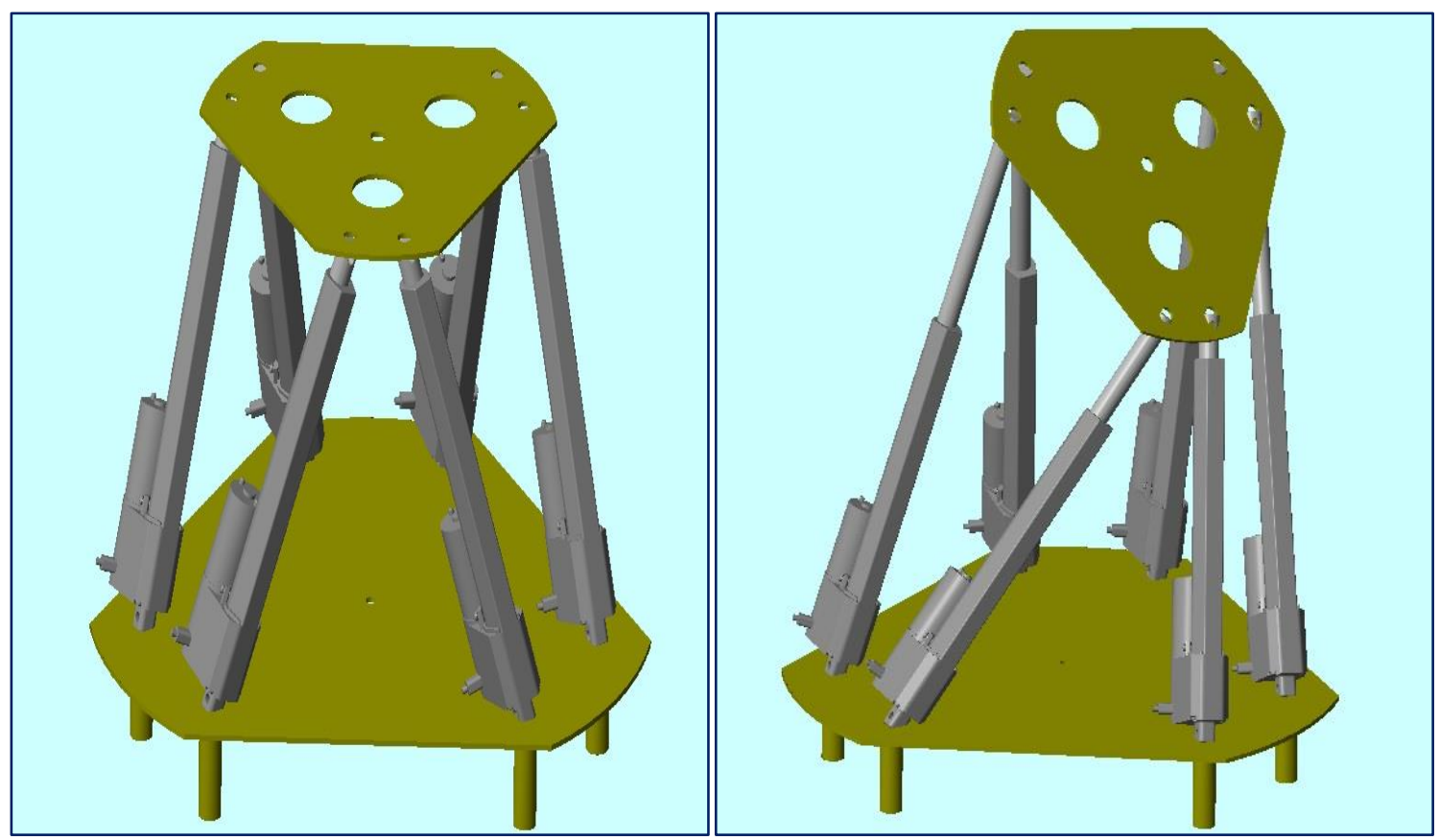

Fig (15): Platform at initial and final position.

The determinant of the Jacobian represented in any time Fig (16), this figure gives insight on the position of the singularities in the configuration, where the $\operatorname{det}(\mathrm{J})=0$ at time between 6.5 and 7 for the given input parameters. And at that time the linkages forces increase to maximum values as in Fig (17).

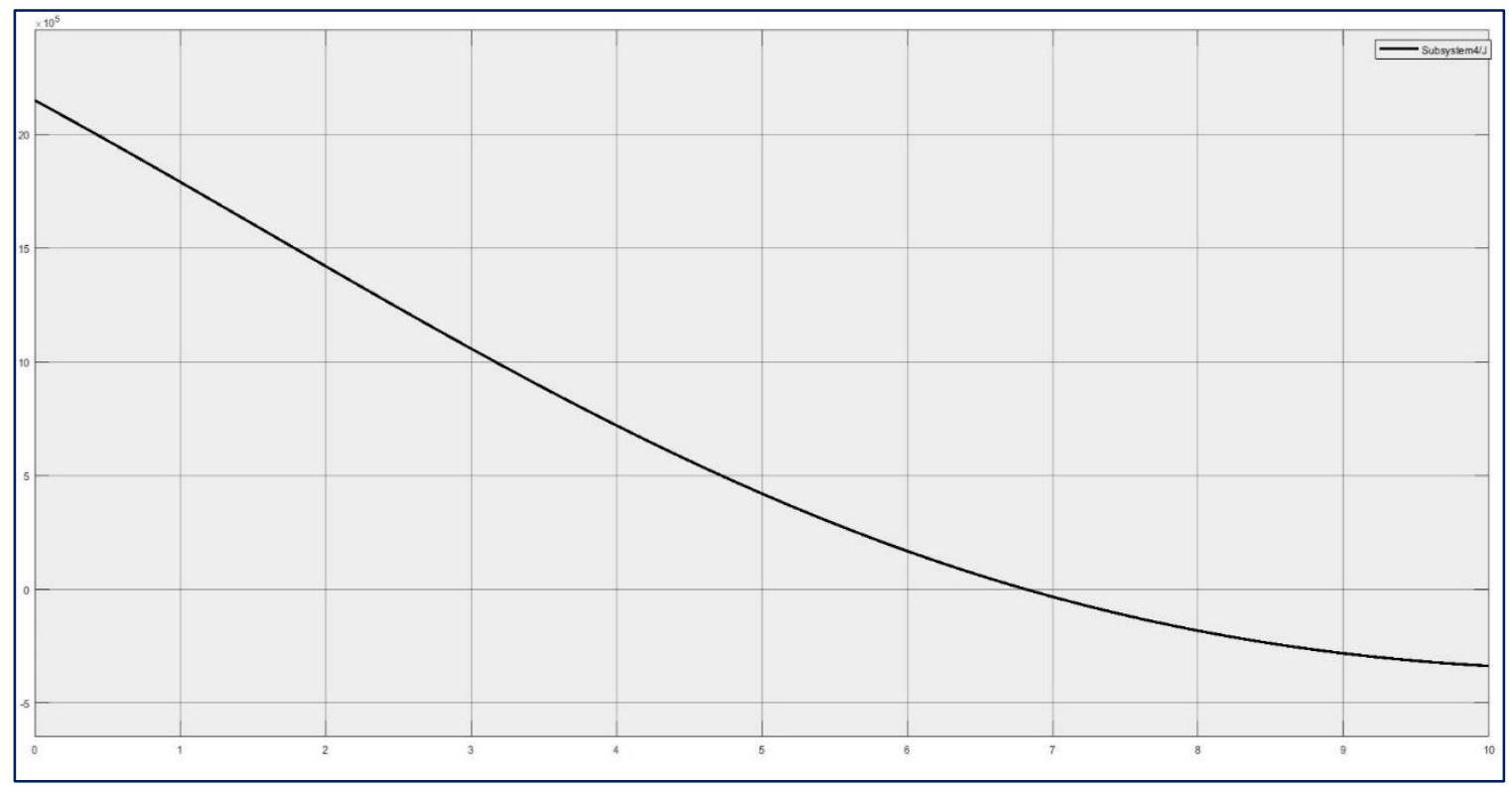

Fig (16): Results of the determinant of the Jacobian matrix. 


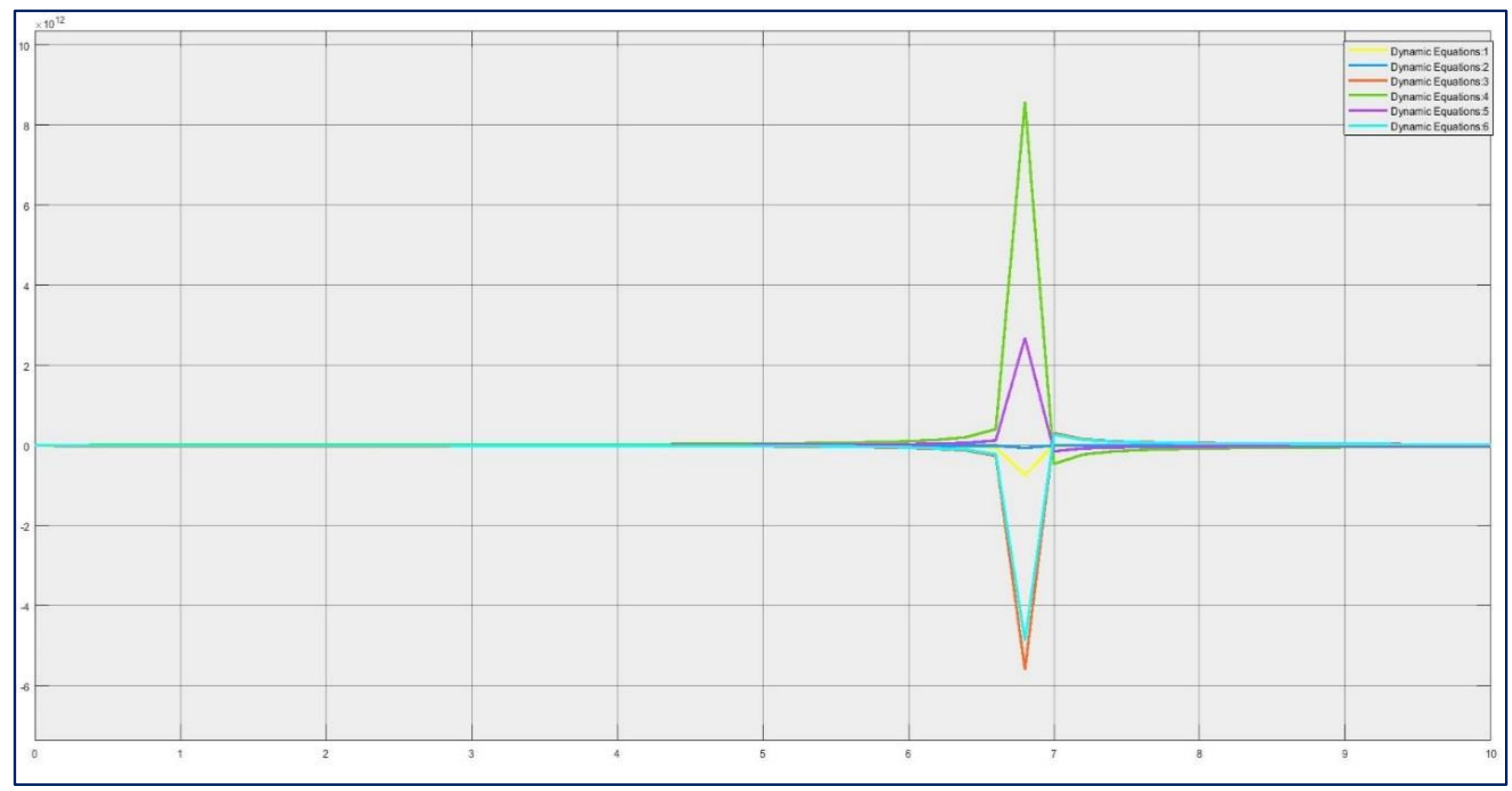

Fig (17): Results of the Linkages forces.

From the above results, these blocks give the coordinates of the singularities during the path of the moving platform and can be used for other inputs (position and orientation) to show if the Trajectories have singular points.

\section{8- Conclusion:}

1- The workspace of the parallel robot has several singular points due to the nature of the mechanism.

2- The singularity detection after derived the kinematics and dynamic analysis which is done in the Matlab software by building blocks diagram in Simulink package.

3- In these blocks, the coordinates of singular points in the workspace verified in both kinematics and dynamic calculation for Gogh-Stewart robot manipulator.

4- The Simulink block can be used in other work to check if the path of trajectories has a singular point.

\section{CONFLICT OF INTERESTS.}

- There are no conflicts of interest.

\section{9- References:}

[1] Q. Jiang and C. M. Gosselin, "the maximal singularity-free orientation workspace for the Gough-Stewart platform," Mech. Mach. Theory, vol. 44, no. 6, pp. 1281-1293, 2009.

[2] A. Peidró, O. Reinoso, A. Gil, J. M. Marín, and L. Payá, "A Virtual Laboratory to Simulate the Control of Parallel Robots," IFAC-PapersOnLine, vol. 48, no. 29, pp. 19-24, 2015.

[3] Y. Cao, W. Ji, Z. Li, H. Zhou, and M. Liu, "Orientation-singularity and nonsingular orientationworkspace analyses of the Stewart-Gough platform using unit quaternion representation," 2010 Chinese Control Decis. Conf. CCDC 2010, pp. 2282-2287, 2010.

[4] G. Lebret, K. Liu, and F. L. Lewis, "Dynamic analysis and control of a Stewart platform manipulator," J. Robot. Syst., vol. 10, no. 5, pp. 629-655, 1993.

[5] D. Stewart, “A Platform with Six Degrees of Freedom,” Proc. Inst. Mech. Eng., vol. 180, no. 1, pp. 371$386,1965$. 
[6] H. Pendar, M. Mahnama, and H. Zohoor, "Singularity analysis of parallel manipulators using constraint plane method," Mech. Mach. Theory, vol. 46, no. 1, pp. 33-43, 2011.

[7] Q. Jiang and C. M. Gosselin, "Determination of the maximal singularity-free orientation workspace for the Gough - Stewart platform," Mech. Mach. Theory, vol. 44, no. 6, pp. 1281-1293, 2009.

[8] G. Liu, Y. Lou, and Z. Li, "Singularities of parallel manipulators: A geometric treatment," IEEE Trans. Robot. Autom., vol. 19, no. 4, pp. 579-594, 2003.

[9] R. Jha, D. Chablat, F. Rouillier, and G. Moroz, "An Algebraic Method to Check the Singularity-Free Paths for Parallel Robots," Vol. 5C 39th Mech. Robot. Conf., p. V05CT08A002, 2015.

[10]B. Li, Y. Cao, Q. Zhang, and C. Wang, "Singularity representation and workspace determination of a special class of the Gough-Stewart platforms," Int. J. Adv. Robot. Syst., vol. 10, 2013.

[11]T. Charters, "Detecting Singularities of Stewart Platforms The Inverse Problem : Lengths as a Function of Position," vol. 1, pp. 66-80, 2009.

[12]J.-P. Merlet, Parallel Robots, vol. 74. 2000.

[13]H. M. Alwan, "Modeling of Gough Stewart Robot Manipulator Inverse Kinematics by Using MSC ADAMS Software Abstract : 1- Introduction :," J. Univ. Babylon Eng. Sci., vol. Vol. (26), no. 26, pp. 266-281, 2018.

[14]S. Küçük, "Serial and Parallel Robot Manipulators- Kinematics, dynamics, control and optimization," InTech. p. 468, 2012.

[15]M. A. Hassan, "The Geometrical Analysis Accuracy for Parallel Robotic Mechanisms," Eng. \& Tech. Journal, vol. 29. p. No.15, 2011.

[16]H. B. Guo and H. R. Li, "Dynamic analysis and simulation of a six degree of freedom Stewart platform manipulator,” Proc. Inst. Mech. Eng. Part C J. Mech. Eng. Sci., vol. 220, no. 1, pp. 61-72, 2006. 
Journal of University of Babylon for Engineering Sciences, Vol. (27), No. (1): 2019.

\section{تصميم برنامج بالسميولنك لاكتثاف الثذوذ في مساحة العمل لربوت كووف ستيوورت

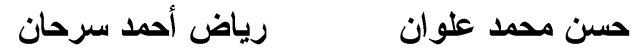 قسم هندسة المبكانيكية، الجامعة التنكنولوجية، بغد/د، العراق}

20071@uotechenology.edu.iq me.21328@uotechnology.edu.iq

الخلاصة:

هذه البحث ينعامل مع الروبوت كووف ستيوورت، الذي يحتوي على ست درجات من الحرية، وست مشغلات، وقاعدة ثابتة،

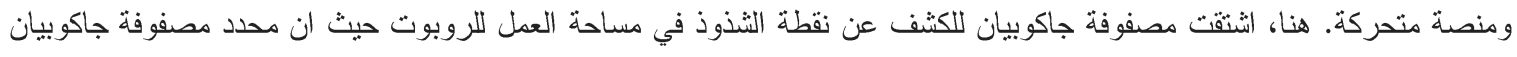
تساوي الصفر ثم اثتقت معادلة الحركة من التحليل الديناميكي بو اسطة طريقة لاكر انج للتحقق من نقاط الثنذوذ تنطابق مع نقاط الجاكوبيان

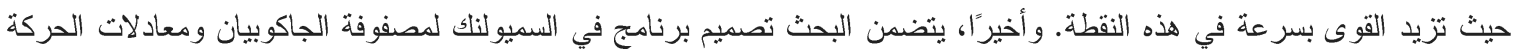

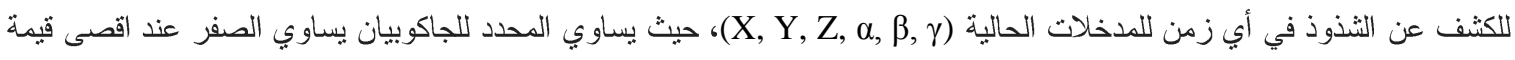
للقوى. الكلمات الدالة: انسان الي، كووف ستيوورت، سيمولنك، جاكو بيان، التحليل الديناميكي، الثذوذ. 